IFN Working Paper No. 1178, 2017

\title{
Cross-border Exchange and Sharing of Generation Reserve Capacity
}

Fridrik M. Baldursson, Ewa Lazarczyk, Marten Ovaere and Stef Proost 


\title{
Cross-border exchange and sharing of generation
}

\author{
reserve capacity
}

Fridrik M. Baldursson ${ }^{1,3}$, Ewa Lazarczyk ${ }^{1,4}{ }^{*}$, Marten Ovaere ${ }^{2}$, and Stef Proost ${ }^{2}$

${ }^{1}$ Reykjavik University, School of Business

${ }^{2} \mathrm{KU}$ Leuven, Department of Economics

${ }^{3}$ University of Oslo

${ }^{4}$ Research Institute of Industrial Economics, IFN

July 25, 2017

This paper develops a stylized model of cross-border balancing. We distinguish three degrees of cooperation: autarky, reserves exchange and reserves sharing. The model shows that TSO cooperation reduces costs. The gains of cooperation increase with cost asymmetry and decrease with correlation of real-time imbalances. Based on actual market data of reserves procurement of positive and negative automatic frequency restoration reserves in Belgium, France, Germany, the Netherlands, Portugal and Spain, we estimate the procurement cost decrease of exchange to be $€ 160$ million per year and of sharing to be $€ 500$ million per year. The model also shows that voluntary cross-border cooperation could be hard to achieve, as TSOs do not necessarily have correct incentives.

Keywords: Cross-border balancing, generation reserves, multi-TSO interactions, 
electricity transmission reliability

\section{Introduction}

Transmission System Operators (TSOs) are responsible for the security of their transmission system. They use upward and downward reserves to deal with imbalances, caused by unanticipated outages and forecast errors of demand and intermittent supply. Historically, each TSO procured and activated its reserves in its own zone. However - following cooperation in forward markets, the day-ahead market and the intraday market - some TSOs in Europe and the United States recently started cross-border cooperation of reserves.

The benefits of cross-border cooperation of reserves have already been studied in the literature. Most of the literature presents case study results. Vandezande et al. (2009) estimate that a Belgium-Netherlands balancing market would have decreased procurement and activation costs by $29-44 \%$ in 2008 , depending on the availability of cross-border capacity. Likewise, Van den Bergh et al. (2017) estimate the benefits of cross-border activation of reserves to be around $€ 25$ million a year for a case study of the 2013 Central Western European electricity system (Belgium, France, Germany and the Netherlands). However, they find lower benefits of cooperation if transmission constraints are neglected during cross-border procurement. Farahmand et al. (2012) study the integration of the balancing and procurement markets of Northern Europe, Germany and the Netherlands. They estimate savings of approximately $€ 204$ million per year for exchange of balancing energy and $€ 153$ million per year for exchange of reserve capacity. This last number is in line with our estimation of $€ 160$ million per year for exchange between Belgium, France, Germany, the Netherlands, Portugal and Spain. Gebrekiros et al. (2013) find only

\footnotetext{
*Corresponding author: Ewa Lazarczyk Carlson, Email: ewalazarczyk@ru.is
} 
a reduction of $2 \%$ of procurement costs in a small numerical illustration. van der Weijde and Hobbs (2011) quantify the inter-market benefits using a stylised 4-node network. They find that the benefits of coordinating balancing markets generally exceed unit commitment benefits. In a future with a $45 \%$ penetration of renewable generation, Mott MacDonald (2013) estimates operational cost savings of exchange and sharing of reserves on European scale in the order of $€ 3$ billion a year. They assume that the increased intermittent and unpredictable generation capacity results in increased volumes of imbalances.

The case study approach in the literature means that there is still a lack of understanding, whether and to what extent TSO cross-border cooperation is economically efficient for each TSO zone and for the region as a whole. The contribution of this paper is to present a general model that analyses three degrees of TSO cooperation in reserves provision. First, we examine autarkic TSO reserve provision - a non-cooperative TSO equilibrium. Next we study the supply efficiency of reserves exchange, where a TSO can acquire reserve capacity in the adjacent TSO area. The last case investigates reserves sharing. Reserves sharing leads to both supply efficiency and dimensioning efficiency. We show that each step in the integration of zones results in progressively lower expected socio-economic costs. We also present a numerical example in order to illustrate the three scenarios. In addition, to get an understanding of their order of magnitude, we estimate the possible cost decrease of cross-border procurement of generation reserves in Central West Europe and Iberia, based on publicly available procurement data. Lastly, we show that the gains of cooperation are not equally distributed across TSOs. Some TSOs may even experience an increase of procurement costs, which makes voluntary cross-border cooperation harder to achieve. As the European balancing guideline does not specify the details of inter-TSO agreements, there is, however, room for bargaining.

The paper is organised as follows. The next section describes various concepts of electricity balancing, together with types and examples of cross-border balanc- 
ing mechanisms. Section 3 introduces the model and analyses different degrees of cooperation of cross-border reserves procurement. In section 4, we estimate the possible cost decrease of cross-border procurement of generation reserves in Central West Europe and Iberia. Next, section 5 studies the implementation of cross-border reserves procurement. Section 6 concludes.

\section{$2 \quad$ Electricity balancing}

Electricity balancing is the continuous process, in all time horizons, through which TSOs ensure that a sufficient amount of upward and downward reserves are available to deal with real-time imbalances between supply and demand in their electricity transmission system. Imbalances occur due to forecast errors of demand and renewable supply and unforeseen events such as line failures and generation outages. If imbalances between supply and demand persist for a certain period of time, the electricity system could collapse, leading to a blackout.

Most transmission systems consist of different interconnected networks, which are each governed by one TSO. Since system frequency is shared on all voltage levels of a synchronous area, due to the technical characteristics of electricity, power system reliability is considered to be a common good. That is, a non-excludable but rival good. This means that a MW of power can only be used once and that it is technologically difficult to prevent interconnected TSOs from using more than they provide. Underprovision of reserves in one TSO zone could thus lead to a widespread blackout throughout the synchronous area. Therefore, to prevent this 'Tragedy of the Commons', all TSOs in a synchronous area are obliged to provide reserves.

Figure 1 shows the two stages of electricity balancing: procurement and activation. First, to ensure that sufficient reserves are available for real-time balancing, TSOs procure or contracts an amount of reserves - so-called reserve capacity or 
balancing capacity - in advance. ${ }^{1}$ This reserve requirements, $R$, is stipulated by network codes and guidelines. To determine the least-cost procurement of reserve capacity to meet the reserve requirement, the TSO holds an open bidding process for each type of reserves ${ }^{2}$ for a given future contracting period. Balancing service providers can submit reserve capacity bids, indicating the size [MW] and the price of the bid [€/MW/hour availability]. In the illustration of Figure 1, bid 1, bid 2 and part of bid 3 are accepted in the procurement phase to meet a reserve requirement $R$. Accepted bids are obliged to be available throughout the contracting period. Second, in each activation period ${ }^{3}$ of the contracting period the TSO holds another open bidding process where both the procured reserve capacity and available non-procured capacity submit balancing energy bids. Bids are accepted by financial merit order to meet the real-time imbalance or reserve need $r_{t}$ of the system. Accepted positive bids increase their generation, while accepted negative bids decrease their generation. In return, they receive the activation price $p_{\text {act }}$. In the illustration of Figure 1, bid 2, part of bid 3 and an additional non-procured bid are accepted in the activation phase to meet the real-time imbalance $r_{t} .{ }^{4}$

In many TSO zones procurement and activation is more complex than the explanation above. For example, some TSOs co-optimise the market clearing of different types of reserves or assess the reserve capacity bid and the balancing energy bid

\footnotetext{
${ }^{1}$ Even network operators with a real-time balancing spot market, like CAISO and Transpower, still procure some reserve capacity in advance. CAISO procures in the day-ahead market and hour-ahead market (Zhou et al., 2016), while Transpower holds a yearly tender for long-term contracts (Transpower, 2013). According to Transpower (2013), the procurement costs are $€ 46.7$ million per year.

${ }^{2}$ In Europe, three main categories of reserves exist: (1) Frequency Containment Reserves (FCR), which is used for stabilising the frequency after a disturbance; (2) Automatic and Manual Frequency Restoration Reserves (aFRR and mFRR), which bring the frequency back to its setpoint value; and (3) Reserve Replacement (RR), which replace the active reserves such that they are available to react to new disturbances (European Commission, 2017a). These three types are called primary, secondary and tertiary reserves in North America (Ela et al., 2011).

${ }^{3}$ The activation period, also called settlement period, can be 15 mins, 30 mins or 1 hour depending on national market design characteristics. This should be standardized for cooperating TSO zones. According to Neuhoff and Richstein (2016), convergence to the largely used $15 \mathrm{~min}$ period is supported by most.

${ }^{4} \mathrm{An}$ alternative to merit order activation is pro-rata activation. In that case all procured reserves are activated but in proportion to their relative procurement bid size.
} 


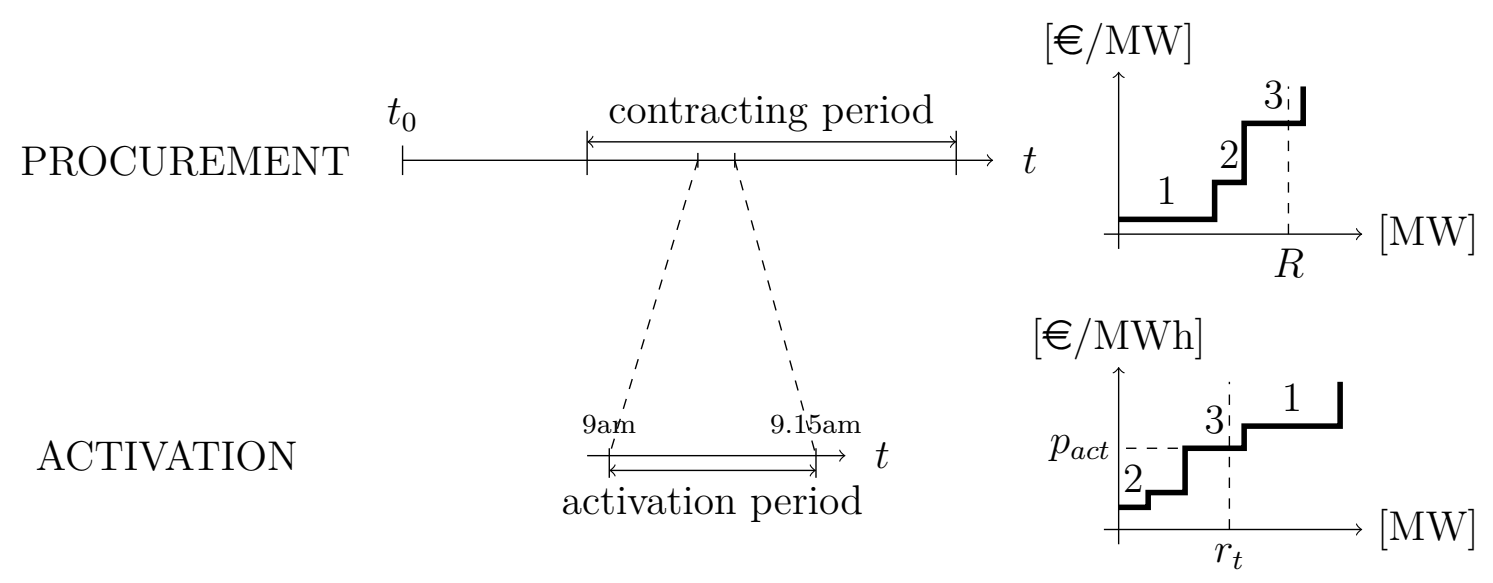

Figure 1: Procurement of reserve capacity and activation of balancing energy.

jointly (50Hertz Transmission GmbH et al., 2014).

Both generation and demand could voluntarily participate in balancing markets, i.e. in both procurement of reserve capacity and activation of balancing energy. However, if the upward reserve need is so large that available reserves are insufficient, the TSO will undertake controlled load-shedding as a last resort to avoid a blackout.

\subsection{Cross-border balancing}

Under the impulse of increasing renewable energy integration, supranational legislation (European Commission, 2017b,a), and a general drive for more cost efficiency and reliability, some TSOs have started to coordinate electricity balancing between neighbouring TSO zones. Often cited benefits of cross-border balancing include a more efficient use of electricity generation, including reduced renewable energy curtailment (Mott MacDonald, 2013); reduced reserve needs (NREL, 2011); a higher reliability level (Van den Bergh et al., 2017); internalisation of external effects on neighbouring TSOs (Tangerås, 2012); a standardization of the rules and products, which creates a level-playing field; and improved market liquidity, which increases competition (Hobbs et al., 2005). In the end, all these benefits decrease the socio-economic cost of balancing. This paper focuses on the first two of the 
above-mentioned benefits:

(A) Supply efficiency: balancing services, both procurement of reserve capacity to meet reserve requirements and activation of balancing energy to meet realtime imbalances, are supplied by the cheapest balancing service providers. That is, if the market is enlarged, expensive balancing services in one part of the market can be substituted for cheaper ones in a different part of the market. The scope for supply efficiency depends on the difference of procurement and activation costs between cooperating TSO zones.

(B) Dimensioning efficiency: less procurement of reserve capacity is needed if a TSO in need of capacity can use idle reserve capacity of adjacent TSO zones.

Cross-border cooperation yields benefits both in procurement of reserve capacity and activation of balancing energy. Table 1 shows the different degrees of cooperation that are possible in procurement and in activation.

Table 1: Degrees of cooperation in cross-border balancing between TSO zones.

\begin{tabular}{cl}
\hline \multicolumn{1}{c}{$\begin{array}{c}\text { PROCUREMENT } \\
\text { of reserve capacity }\end{array}$} & \multicolumn{1}{c}{$\begin{array}{c}\text { ACTIVATION } \\
\text { of balancing energy }\end{array}$} \\
\hline $\begin{array}{l}\text { To meet the reserve requirements resulting } \\
\text { from reserve dimensioning }\end{array}$ & $\begin{array}{c}\text { To meet real-time imbalances resulting from } \\
\text { forecast errors and unforeseen events }\end{array}$ \\
\hline $\begin{array}{c}\text { Autarky: no cross-border cooperation } \\
\text { Exchange: procure reserves in other zones }\end{array}$ & $\begin{array}{l}\text { Autarky: no cross-border cooperation } \\
\text { Imbalance netting: avoid counteracting } \\
\text { Sharing: multiple zones take into account } \\
\text { the same reserves }\end{array}$ \\
\hline
\end{tabular}

First, the three degrees of cooperation in procurement of reserve capacity are autarky, exchange and sharing. Reserves exchange makes it possible to procure part of the required level of reserves in adjacent TSO zones. These reserves are contractually obliged to be available for activation by the contracting TSO and they can only contribute to meeting this TSO's required level of reserves. Reserves exchange 
changes the geographical distribution of reserves. More reserves are procured in cheap TSO zones and less in expensive TSO zones. Reserves exchange increases supply efficiency by decreasing the procurement costs.

Reserves sharing allows multiple TSOs to take into account the same reserves to meet their reserve requirements resulting from reserve dimensioning. ${ }^{5}$ A TSO in need of balancing energy can use this shared capacity, if other TSOs do not. Reserves sharing leads to both supply efficiency and dimensioning efficiency.

Second, the three degrees of cooperation in activation of balancing energy are autarky, imbalance netting and exchange. Imbalance netting avoids counteracting activation of balancing energy in adjacent TSO zones. For example, activating upward reserves in response to a negative imbalance in one TSO zone, and separately activating downward reserves in response to a positive imbalance in another TSO zone, is inefficient since counteracting imbalances naturally net out on synchronous networks. A simple coordination of imbalances could avoid this inefficiency. Imbalance netting is a constrained version of exchange of balancing energy.

Exchange of balancing energy is a further degree of cooperation in activation of balancing energy. It implies that cooperating TSOs construct a common merit order of balancing energy bids and select the least-cost activation that meets the net imbalance of the joint TSO zone. ${ }^{6}$ Imbalance netting and exchange of balancing energy increase supply efficiency by decreasing the activation costs.

Although in the remainder of this paper, we only study procurement of reserve capacity, it should be noted that activation is a prerequisite for implementing reserves sharing. It only makes sense to decrease the total amount of procured capacity if balancing energy is activated based on a common merit order and imbalances are netted out. Exchange of reserve capacity, however, is possible without

\footnotetext{
${ }^{5}$ In practice, reserves exchange and sharing is not limitless. Baldursson et al. (2016) summarize the limits on reserves exchange and sharing, as imposed by the EU guideline on electricity transmission system operation (European Commission, 2017b).

${ }^{6}$ Other market arrangements, like BSP-TSO and an additional voluntary pool, are also possible (Doorman and Van der Veen, 2013).
} 
cooperation in activation.

\subsection{Examples of cross-border balancing}

Balancing and reserve cooperation between TSOs is still in its infancy. However, a few examples of successful cooperation exist in Europe and the United States:

In Europe, ENTSO-E is reviewing a number of pilot projects with the aim to test the feasibility of a multi-TSO cooperation on the cross border procurement of reserve capacity and activation of balancing energy. First, the International Grid Control Cooperation (IGCC) is a project of imbalance netting of frequency restoration reserves (FRR) to avoid counteracting activation of balancing energy (Just, 2015). The IGCC was launched in 2012 and currently consists of TSOs from Austria, Belgium, Czech Republic, Denmark, France, Germany, the Netherlands and Switzerland. Second, a part of this group of countries (Austria, Belgium, France, Germany, the Netherlands and Switzerland) also jointly procure frequency containment reserves (FCR) in a weekly auction. Third, the Trans-European Replacement Reserves Exchange (TERRE) is established between UK, France, Great Britain, Greece, Italy, Spain, Portugal and Switzerland. The project aims to jointly activate replacement reserves (ENTSO-E, 2016; Neuhoff and Richstein, 2016). A fourth example of TSO cooperation is the Regulating Power Market (RPM), which was established in 2002 between Denmark, Finland, Norway and Sweden. The RPM is a common merit order of manual frequency restoration reserves (mFRR) activation.

In the United States, a cross-border energy imbalance market (EIM) was established between CAISO and PacifiCorp in November 2014. As of 2016 the crossborder EIM consists of five network operators and public utilities in eight states. According to CAISO (2017), the benefits amounted to $\$ 173.72$ million between 2014Q4 and 2017Q2 and are expected to increase even more in the future with an increased share of renewable generation. 


\section{Benefits of cross-border reserves procurement}

This section studies the benefits of cross-border procurement of reserve capacity. We derive analytical expressions for the optimal level of procured reserves and study the associated cost decreases. Each degree of cross-border cooperation is analysed: autarky, reserves exchange and reserves sharing. Transmission constraints are an important issue affecting power grids. In this paper, however, we assume, as a first approximation, that there is enough transmission capacity available to accommodate the flows arising from balancing. Incorporating transmission constraints is an important issue for further research.

\subsection{Model}

This model studies two TSO zones $i=1,2$ that can either not cooperate (autarky), exchange reserves or share reserves. The need for reserves in TSO zone $i$ at a certain instant is denoted by a random variable $r_{i}[\mathrm{MW}]$. This is the real-time imbalance between supply and demand due to a combination of forecast errors of demand and intermittent supply, and failures of generation capacity or transmission components. We denote the joint probability density function of the reserve needs by $f\left(r_{1}, r_{2}\right)$ and the marginal density functions of $r_{1}$ and $r_{2}$ by $f_{1}$ and $f_{2}$ respectively. ${ }^{7}$ The TSO's variable of choice is $R_{i}[\mathrm{MW}$, the quantity of reserves procured for its own zone $i$. The contracting period for the procurement of reserve capacity could be e.g. an hour, a week, a month, or a year. In the model we only focus on procurement of upward reserves. Negative reserve procurement is the mirror analysis and its equations are similarly interpreted.

In this paper we are interested in efficiency gains from exchange or sharing of reserve procurement, not efficient activation as such. Hence, the model does not take reserves activation into consideration and we therefore take marginal generation

\footnotetext{
${ }^{7}$ The joint probability density function $f\left(r_{1}, r_{2}\right)$ will in general depend on the procurement interval and the time to real-time operation.
} 
costs to be equal to zero. Costs of procuring $R_{i}$ of reserve capacity in TSO zone $i$, however, are not zero and are given by $\gamma_{i}\left(R_{i}\right)$, with $\gamma_{i}$ increasing, smooth and convex.

Figure 2 summarizes the order of events. First the TSO at each node $i$ chooses how much reserve capacity $R_{i}$ to procure. In case of exchange or sharing of reserves, the procurement may entail payments between TSOs. Next, in real time, the actual need for reserves $r_{i}$ is observed in each node $i$. The procured reserves will be used to accommodate the reserve needs. In case local reserves are insufficient, TSOs will use exchanged or shared reserves, or, as a last resort, carry out load shedding. Last, settlement payments - if any - are made.

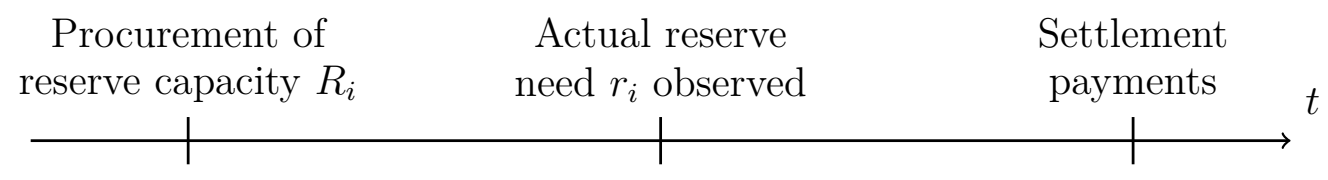

Figure 2: Order of events

\subsection{Optimal autarkic TSO reserve provision}

We first consider the case where there is no trade or exchange of reserves between zones. Thus, each TSO zone operates as an isolated "island". In reality, network codes and guidelines stipulate the quantity of reserves each TSO zone is required to procure. ${ }^{8}$ However, here we pursue an alternative approach by considering the firstbest outcome within this setting, i.e. where TSO $i$ procures a quantity of reserves $R_{i}$ such that expected social surplus in Zone $i$ is maximized. ${ }^{9}$ We assume the value of lost load (VoLL - measured in $€ / M W h$ ) is fixed at $v$ and that electricity demand $D_{i}$ is price inelastic and also valued at $v$. Hence, for a given level of reserve needs $r_{i}$ and procured reserves $R_{i}$ social surplus is given by consumer surplus net of costs

\footnotetext{
${ }^{8}$ Such an exogenous requirement is also standard in reliability management of the day-ahead market, where the N-1 reliability criterion is used instead of balancing the costs of reliability and interruptions (Ovaere and Proost, 2016).

${ }^{9}$ If the reserve requirements of network codes diverge from this first-best optimum (e.g. due to imperfect information or socio-political constraints), costs are higher than in the first-best.
} 
of interruptions (due to unserved demand) and costs of procuring reserves,

$$
S_{i}=v D_{i}-v\left[r_{i}-R_{i}\right]^{+}-\gamma_{i}\left(R_{i}\right)
$$

The TSO selects $R_{i}$ to maximize $E\left[S_{i}\right]$ with respect to $R_{i}$

$$
\max _{R_{i}}\left\{v D_{i}-v \int_{R_{i}}^{\infty}\left[r_{i}-R_{i}\right] f_{i}\left(r_{i}\right) d r_{i}-\gamma_{i}\left(R_{i}\right)\right\}
$$

Equivalently, since demand is inelastic, the TSO can minimize combined costs of interruptions and reserves, i.e.

$$
\min _{R_{i}}\left\{v \int_{R_{i}}^{\infty}\left[r_{i}-R_{i}\right] f_{i}\left(r_{i}\right) d r_{i}+\gamma_{i}\left(R_{i}\right)\right\}
$$

This is the approach we shall use henceforth.

Differentiating (3) we derive the following first-order condition for the optimal quantity of reserves $R_{i}^{a}$ in autarky:

$$
v \operatorname{Pr}\left\{r_{i}>R_{i}^{a}\right\}=\gamma_{i}^{\prime}\left(R_{i}^{a}\right)
$$

The condition (4) is very intuitive: reserves should be procured up to the point where the marginal cost of procurement (right-hand side) is equal to the marginal cost of interruptions (left-hand side). The left-hand side might be interpreted as VoLL times the loss of load probability (LoLP). The second-order condition for minimum is easily seen to be satisfied.

\subsection{Reserves exchange}

We now turn to the case of reserves exchange, which as explained earlier, makes it possible to procure part of the required level of reserves in adjacent TSO zones. We assume here that sufficient transmission capacity is available to accommodate the flows arising from use of reserve capacity in adjacent TSO zones and thus neglect any limits transmission capacity constraints would place on reserves exchange (Van den Bergh et al., 2017). That is, there is only load-shedding if $r_{i}>R_{i}$, irrespective 
of where the reserve capacity is procured. To make the setting non-vacuous we assume that procurement costs are not symmetrical so there is a motive for reserves exchange.

This sections shows that exchange of reserves only leads to supply efficiency, not dimensioning efficiency. We study two variants of reserves exchange. First, that the required level of reserves in each TSO zone is the same as in autarky (regulated reserve levels); and second, that it is adjusted in accordance with procurement prices of reserves exchange (locally optimal reserve levels).

\subsubsection{Regulated reserves levels}

Here we assume, in accordance with the EU guideline on electricity transmission system operation (European Commission, 2017b), that the required level of reserves in each TSO zone is the same as in autarky, i.e. $R_{i}^{a}$.

In the first-best solution for this setting the two TSOs jointly minimise total costs of procurement, subject to the constraint on reserves. That is, the cheapest reserve capacity in the two TSO zones is procured first. This amounts to the following constrained cost minimization

$$
\min _{R_{1}, R_{2}}\left\{\gamma_{1}\left(R_{1}\right)+\gamma_{2}\left(R_{2}\right)\right\} \text { s.t. } R_{1}+R_{2}=R_{1}^{a}+R_{2}^{a}
$$

Note that $R_{i}$ denotes the combined quantity of reserves procured in Zone $i$ by the two TSOs. The side constraint simply says that the overall quantity of reserves procured has to equal the sum of the required reserve levels in the two zones. This minimization problem is easily seen to lead to the following set of equations:

$$
\left\{\begin{array}{l}
\gamma_{1}^{\prime}\left(R_{1}\right)=\gamma_{2}^{\prime}\left(R_{2}\right) \\
R_{1}+R_{2}=R_{1}^{a}+R_{2}^{a} .
\end{array}\right.
$$

That is, overall costs are lowest when the marginal cost of reserve procurement is equal in the two TSO zones. Fig. 3 shows this cost minimization graphically. 


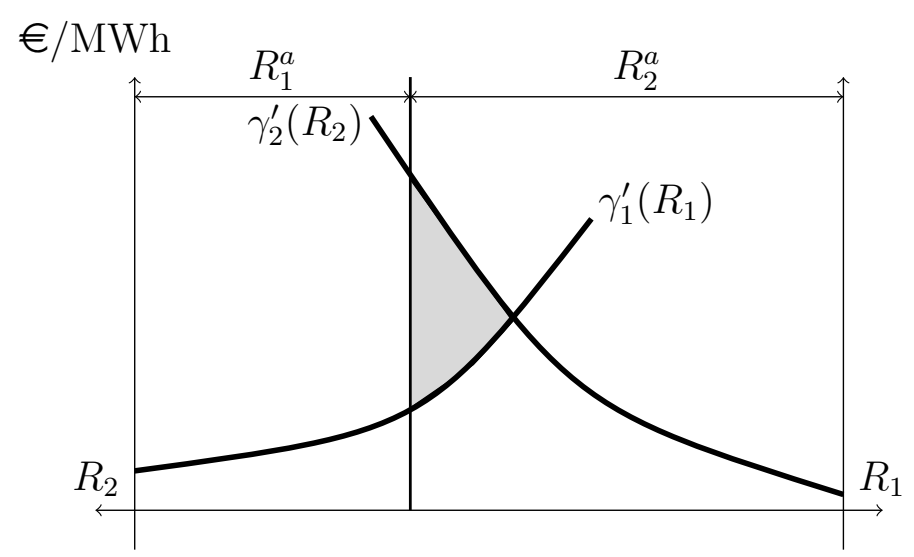

Figure 3: Cost minimization under reserves exchange between two TSO zones

The axis runs from left to right for TSO zone 1 and from right to left for TSO zone 2. The upward sloping lines are the marginal procurement costs in Zone 1 and 2. Clearly, if costs are symmetrical in the two zones, then there is no reason to exchange reserves and the optimal solution is for each TSO to procure reserves within his own zone. If costs are asymmetrical, then there is a rationale for exchange. The grey area in the figure represents the reduction of procurement costs under the optimal procurement of reserves as compared to the costs in autarky where exchange is not possible and each zone supplies its own required reserves.

\subsubsection{Locally optimal reserves levels}

In the previous section we considered reserves exchange where required reserve levels were assumed to be given by regulation. ${ }^{10}$ Since the regulatory levels in our model were set so as to match marginal costs of interruptions and reserves, the resulting outcome after opening up for exchange is, however, no longer an optimum: marginal interruption costs no longer match marginal costs of procuring reserves; it will be tempting to lower required reserves in the cheaper zone, where marginal procurement costs have risen, and raise them in the more expensive zone, where they have fallen.

\footnotetext{
${ }^{10}$ We assumed the regulation to hold TSOs to autarkic levels, even after exchange is allowed, but in principle the regulation could be set at any arbitrary level.
} 
So another scenario is possible when TSOs are allowed to adjust their reserves levels in accordance with prices; this would seem likely to be the tendency over the longer run.

Again, we begin by considering the first-best solution for the present setting. This involves finding the jointly optimal reserve levels, viz. solving

$$
\min _{R_{1}, R_{2}, R_{1}^{e}, R_{1}^{e}} \text { s.t. } R_{1}+R_{2}=R_{1}^{e}+R_{2}^{e}\left\{\sum_{i=1}^{2} v \int_{R_{i}^{e}}^{\infty}\left[r_{i}-R_{i}^{e}\right] f_{i}\left(r_{i}\right) d r_{i}+\sum_{i=1}^{2} \gamma_{i}\left(R_{i}\right)\right\}
$$

where $R_{j}$ is the amount of reserves procured in Zone $j$ (as before) and $R_{i}^{e}$ is the amount of reserves procured by TSO $i$.

It is readily seen that the optimal solution in this case is determined by the condition that all marginal costs be equal, both across zones and cost types. In other words,

$$
\left\{\begin{array}{l}
v \operatorname{Pr}\left\{r_{1}>R_{1}^{e}\right\}=v \operatorname{Pr}\left\{r_{2}>R_{2}^{e}\right\}=\gamma_{1}^{\prime}\left(R_{1}\right)=\gamma_{2}^{\prime}\left(R_{2}\right)^{11} \\
R_{1}+R_{2}=R_{1}^{e}+R_{2}^{e}
\end{array}\right.
$$

\subsection{Reserves sharing}

Reserves sharing allows multiple TSOs to draw on the same reserves resources to meet their required level of reserves when it comes to operation. Recall that while exchange of reserves only leads to supply efficiency, reserves sharing leads to both supply efficiency and dimensioning efficiency. As before, we assume that transmission capacity is sufficient to always accommodate the flows arising from use of reserve capacity in adjacent TSO zones. That is, there is only load-shedding

\footnotetext{
${ }^{11}$ For simplification we have assumed the VoLL (v) to be identical across zones. In some adjucent markets, e.g. in the EU, estimations of VoLL differ. Different VoLL can easily be taken into account, but would slightly complicate the analysis without significantly changing results. Specifically, the condition that marginal costs of interruption is the same across zones would continue to hold, but the expression for it would change: (Here an expression where $v$ is replaced by $v_{1}$ in the first MC and by $v_{2}$ in the second MC.) In particular, the LoLP would be higher in the zone with the lower VoLL and vice versa
} 
if $r_{1}+r_{2}>R_{1}+R_{2}$.

In our model, reserves sharing amounts to maximizing the surplus of the two zones jointly, in effect uniting them. ${ }^{12}$ As before, since we take demand to be inelastic, this is tantamount to minimizing expected costs of interruptions and procurement:

$$
\min _{R_{1}^{s}, R_{2}^{s}}\left\{v \int_{0}^{\infty} \int_{R_{1}^{s}+R_{2}^{s}}^{\infty}\left[r_{1}+r_{2}-R_{1}^{s}-R_{2}^{s}\right] f\left(r_{1}, r_{2}\right) d r_{1} d r_{2}-\gamma_{1}\left(R_{1}^{s}\right)-\gamma_{2}\left(R_{2}^{s}\right)\right\}
$$

The optimal reserve capacities when reserves sharing is allowed, $R_{1}^{s}$ and $R_{2}^{s}$, are determined from the following first-order conditions:

$$
\left\{\begin{array}{l}
v \operatorname{Pr}\left\{r_{1}+r_{2}>R_{1}^{s}+R_{2}^{s}\right\}=\gamma_{1}^{\prime}\left(R_{1}^{s}\right) \\
v \operatorname{Pr}\left\{r_{1}+r_{2}>R_{1}^{s}+R_{2}^{s}\right\}=\gamma_{2}^{\prime}\left(R_{1}^{s}\right)^{13}
\end{array}\right.
$$

which are derived by differentiation of (9) with respect to $R_{1}^{s}$ and $R_{2}^{s}$, respectively. The first-order equations imply that marginal costs of reserves procurement are equal to VoLL times the loss of load probability in the two zones together. Clearly, this implies that marginal costs of procurement are equal at the optimal levels of procurement, $\gamma_{1}^{\prime}\left(R_{1}^{s}\right)=\gamma_{2}^{\prime}\left(R_{2}^{s}\right)$. Hence, the costs of reserves procurement are minimized as in reserves exchange, but for different levels of reserves and, hence, also reliability.

\subsection{Efficiency of different degrees of cooperation}

To compare the efficiency of the different degrees of cooperation, we need to compute the total $\operatorname{costs} c^{j}$ for each degree of cooperation $j \in\{a, e, l, s\}$. It leads to the following proposition.

Proposition 1. Each step in the integration of zones results in progressively lower expected socio-economic costs, i.e. $c^{a} \geq c^{e} \geq c^{l} \geq c^{s}$.

\footnotetext{
${ }^{12}$ As a simplification, we neglect any limits on reserves sharing, see Baldursson et al. (2016).

${ }^{13} \mathrm{As}$ in the case of exchange, different VoLL can easily be taken into account, see footnote 11 above
} 
Proof. Recall that for each degree of cooperation $j \in\{a, e, l, s\}, R_{i}^{j}$ is the optimal amount of reserves procured in Zone $i$ and $c^{j}$ is the sum of procurement costs and interruption costs in both TSO zones. By contrast, $R_{i}$ is the amount of reserves procured by TSO $i$. Equation (11) is the sum of procurement costs and interruption costs with autarky. This minimization determines $R_{1}^{a}$ and $R_{2}^{a}$. Adding an additional variable $R_{1}^{e}$ leads to equal interruption costs and weakly lower procurement costs in equation (12). The inequality is strict if $R_{1}^{e} \neq R_{1}^{a}$ and $R_{2}^{e} \neq R_{2}^{a}$. Adding even more variables to allow a trade off between procurement costs and interruption costs causes equation (13) to be weakly lower than equation (12). Again the inequality is strict if $R_{1}^{e} \neq R_{1}^{a}$ and $R_{2}^{e} \neq R_{2}^{a}$. To proof the last inequality, notice that equation (13) equals equation (14) if the correlation of reserve needs is one. If the correlation is lower than one, both procurement costs and interruption costs decrease.

$$
\begin{aligned}
& c^{a}=\min _{R_{1}^{a}, R_{2}^{a}}\left\{v E\left[r_{1}-R_{1}^{a}\right]^{+}+v E\left[r_{2}-R_{2}^{a}\right]^{+}+\gamma_{1}\left(R_{1}^{a}\right)+\gamma_{2}\left(R_{2}^{a}\right)\right\} \\
& \geq c^{e}=\min _{R_{1}^{e}}\left\{v E\left[r_{1}-R_{1}^{a}\right]^{+}+v E\left[r_{2}-R_{2}^{a}\right]^{+}+\gamma_{1}\left(R_{1}^{e}\right)+\gamma_{2}\left(R_{1}^{a}+R_{2}^{a}-R_{1}^{e}\right)\right\} \\
& \geq c^{l}=\min _{R_{1}^{l}, R_{1}, R_{2}}\left\{v E\left[r_{1}-R_{1}\right]^{+}+v E\left[r_{2}-R_{2}\right]^{+}+\gamma_{1}\left(R_{1}^{l}\right)+\gamma_{2}\left(R_{1}+R_{2}-R_{1}^{l}\right)\right\} \\
& \text { with } R_{1}+R_{2}=R_{1}^{l}+R_{2}^{l} \\
& \geq c^{s}=\min _{R_{1}^{s}, R_{2}^{s}}\left\{v E\left[r_{1}+r_{2}-R_{1}^{s}-R_{2}^{s}\right]^{+}+\gamma_{1}\left(R_{1}^{s}\right)+\gamma_{2}\left(R_{2}^{s}\right)\right\}
\end{aligned}
$$

This can also be shown graphically. Figure 4 shows the socio-economic costs for each degree of cross-border cooperation. The increasing lines are the marginal procurement costs to reach a certain reliability level $\rho .{ }^{14}$ As a result, the area below such a line is the total procurement cost to reach reliability level $\rho$ (dark grey area) and interruption costs are $v(1-\rho)$ (light grey area). In aggregate, a higher degree

\footnotetext{
${ }^{14}$ Reliability $\rho \in[0,1]$ can be defined in multiple ways. For example, $\rho=1-$ LOLP, where the loss of load probability (LOLP) is the probability of being in a state of the world where some load shedding is needed; or $\rho=$ fraction of total demanded load [MWh] that is supplied to consumers.
} 
of cooperation leads to lower procurement costs to reach a certain reliability level, i.e. $\gamma^{a}(\bar{\rho})>\gamma^{e}(\bar{\rho})>\gamma^{s}(\bar{\rho})$. Figures $4 \mathrm{a}$ and $4 \mathrm{~b}$ show that moving from autarky to exchange with regulated reserve levels leads to lower procurement costs but leaves interruption costs unchanged, because the reliability level is held fixed. Proceeding to exchange with locally optimal reserve levels (Figure 4c) increases procurement costs but less than the decreases of interruption costs. This analysis also shows that moving from autarky to locally optimal exchange has an ambiguous effect on procurement costs because the cost increase of a higher reliability level can exceed the cost decrease of reserves exchange. The cost decrease depends on the cost asymmetry between procurement costs in both TSO zones. Last, reserves sharing (Figure 4d) leads to an even higher reliability level and thus interruption costs decrease. As before, its effect on procurement costs is ambiguous and depends on the correlation of reserve needs in TSO zones. The next section presents a numerical illustration of the benefits of cross-border cooperation and studies the comparative statics of the main parameters.

\subsection{Numerical illustration and comparative statics}

The benefits of cross-border exchange and sharing of reserve capacity depend on two parameters: the difference in procurement cost in both TSO zones $\left(g_{1}\right.$ and $\left.g_{2}\right)$ and the correlation of reserve needs between TSO zones $\left(\xi=\operatorname{corr}\left(r_{1}, r_{2}\right)\right)$. Supply efficiency increases if procurement costs are more asymmetric and dimensioning efficiency increases if reserve needs are less correlated. Figure 5 plots the sum of interruption costs and procurement costs with reserves exchange and sharing, relative to the costs in autarky, and shows that the benefits of exchange increase with cost asymmetry $\left(g_{1} / g_{2}\right)$ and that the benefits of sharing increase with decreasing reserve need correlation $\xi$.The probability density functions of reserve needs are jointly normal with correlation $\xi$, each with a mean of 0 MW and a variance of 100 MW: $\mathrm{N}(0,100)$. The cost of reserve procurement in Zone $i$ is $\gamma_{i}\left(R_{i}\right)=g_{i} R_{i}^{2}$, with 


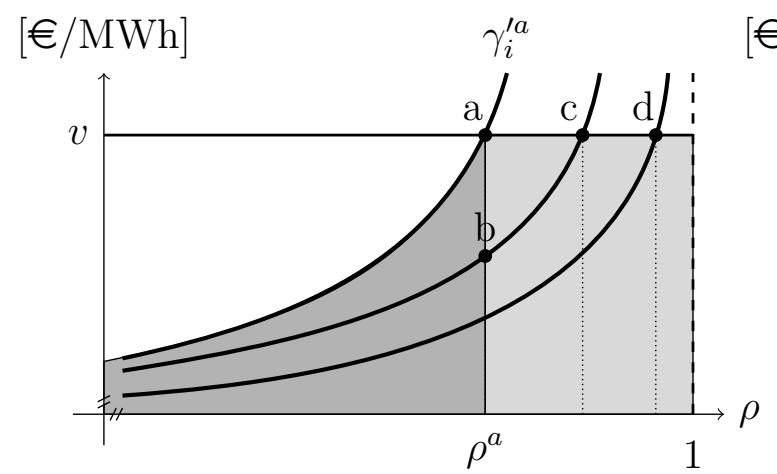

(a) Autarky

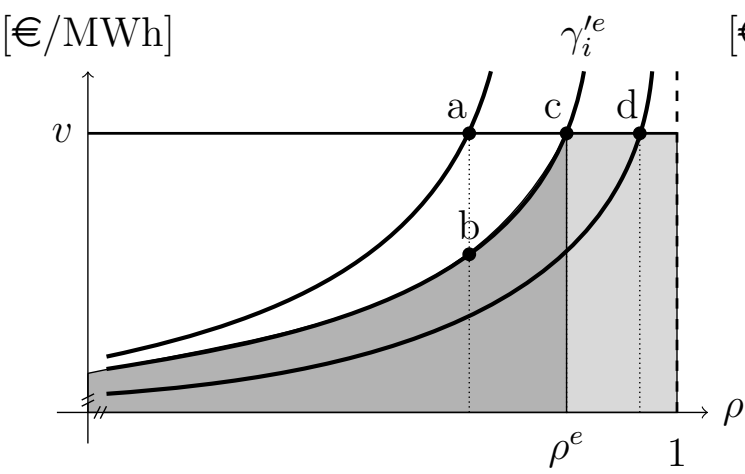

(c) Exchange (locally optimal)

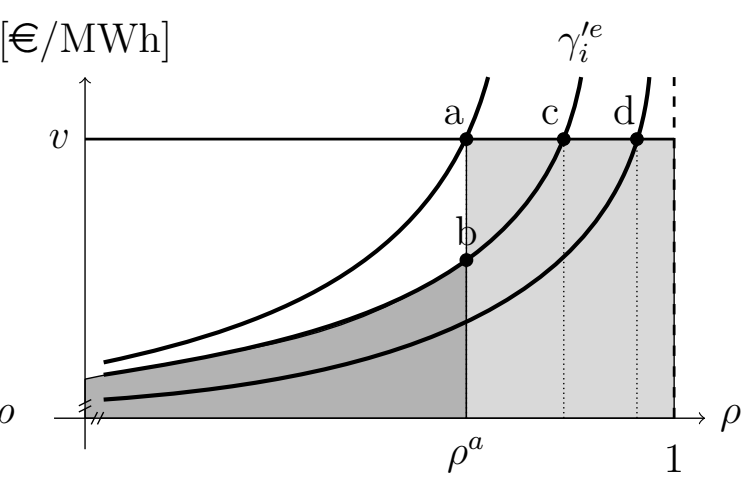

(b) Exchange (regulated)

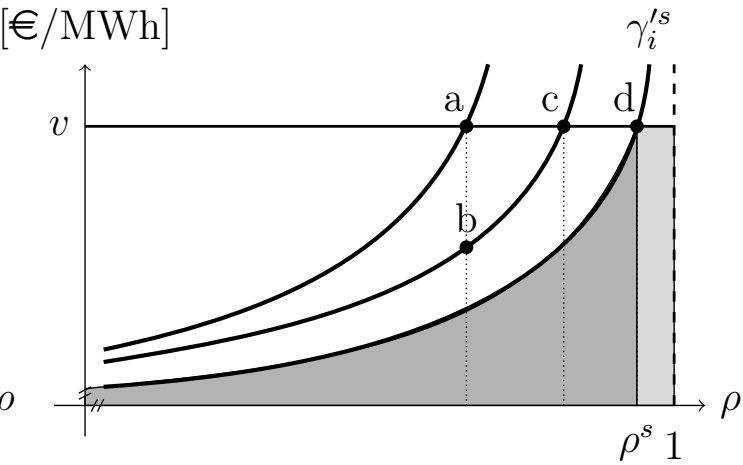

(d) Sharing

Figure 4: Degrees of cooperation: cost efficiency and reliability level.

$g_{1}=g_{2}=1$ at $g_{1} / g_{2}=1$. The VoLL is $10,000 € /$ MWh.

Figure 5 illustrates several issues. First, when the two TSO zones have identical procurement costs, no cost arbitrage is possible and exchange of reserve does not yield any cost reduction. However, reserves sharing leads to a lower reserve need and thus a lower cost. Second, when the cost of reserve procurement differs between TSO zones, reserves exchange does yield a cost reduction. For example, when the cost of reserve procurement is higher in TSO zone 1, TSO 1 procures part of its reserve obligation with reserve capacity providers in TSO zone 2. Third, the cost reduction decreases when the reserve needs in the two TSO zones are more correlated. When the reserve needs are fully correlated, reserves sharing yields almost no additional cost reduction compared to reserves exchange.

Figure 5 also illustrates that the cost reduction increases when reserve procurement costs become more asymmetric and reserve needs are less correlated. With low 


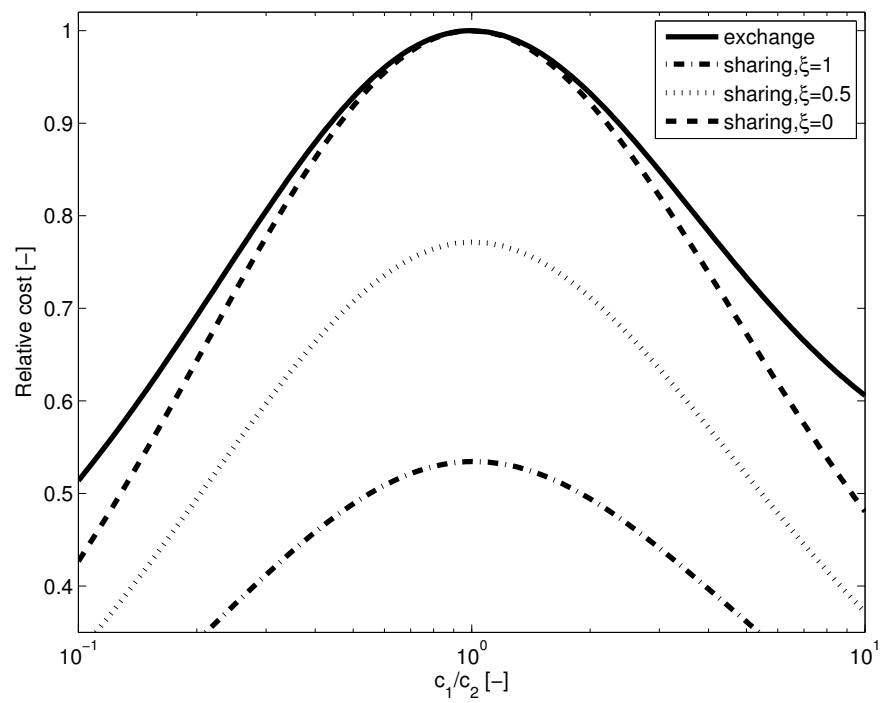

Figure 5: Relative cost of reserves exchange and reserves sharing, as a function of the cost asymmetry $\left(g_{1} / g_{2}\right)$ and the reserve needs correlation $(\xi)$.

cost asymmetry and low correlation, reserves sharing yields the major part of the cost reduction, while with high cost asymmetry and a high correlation, reserves exchange yields the major part of the cost reduction. With symmetric costs and high correlation, cross-border cooperation in reserves yields very little cost reduction.

Table 2 analyses in detail the reserves, total procurement costs and total interruption costs for the values used in Figure 5, with $g_{1}=2$ and $g_{2}=1$. The table shows that sharing reduces the total amount of procured reserves and decreases interruption costs (increases the reliability level). Note that sharing with correlation $\xi=1$ is equal to exchange with locally optimal reserves.

Table 2: Reserves and costs in Zone 1 and 2: $g_{1}=2, g_{2}=1(P C=$ procurement cost, $I C=$ interruption cost).

\begin{tabular}{lcccccccc}
\hline & $R_{1}$ & $R_{2}$ & $R_{1}+R_{2}$ & $\begin{array}{c}\text { Relative } \\
\text { reserves }\end{array}$ & PC & IC & $\begin{array}{c}\text { Total } \\
\text { costs }\end{array}$ & $\begin{array}{c}\text { Relative } \\
\text { costs }\end{array}$ \\
\hline Autarky & 23.5 & 25.7 & 49.2 & $100 \%$ & 1763 & 479 & 2242 & $100 \%$ \\
Exchange & 16.4 & 32.8 & 49.2 & $100 \%$ & 1611 & 479 & 2090 & $93.2 \%$ \\
Sharing $\xi=1$ & 16.5 & 33.0 & 49.6 & $100.8 \%$ & 1638 & 429 & 2067 & $92.2 \%$ \\
Sharing $\xi=0.5$ & 14.6 & 29.1 & 43.7 & $88.9 \%$ & 1273 & 324 & 1597 & $71.2 \%$ \\
Sharing $\xi=0$ & 12.2 & 24.4 & 36.6 & $74.4 \%$ & 891 & 217 & 1108 & $49.4 \%$ \\
\hline
\end{tabular}

In addition to cost asymmetry and the reserve needs correlation, three other param- 
eters influence relative costs of reserves exchange and sharing: VoLL $(v)$, procurement costs, and the relative size of the TSO zones. Table 3 compares the relative cost of the base case with a case with higher VoLL, a case with higher procurement costs, and a case where countries differ in size. First, the relative gains of cooperation increase with increasing VoLL, since both the gains of decreased interruption costs and decreased procurement costs are higher. Second, higher procurement costs decrease the relative gains of cooperation. Third, if the TSO zones differ in size $^{15}$ the relative gains of cooperation decrease.

Table 3: Sensitivity of relative costs [\%].

\begin{tabular}{lcccc}
\hline & BASE & $v=10 v_{b}$ & $g_{i}=10 g_{i, b}$ & $\sigma_{2}=6 \sigma_{b}$ \\
\hline Autarky & 100 & 100 & 100 & 100 \\
Exchange & 93.2 & 92 & 95.5 & 96.7 \\
Sharing $\xi=1$ & 92.2 & 91.2 & 94.0 & 96.1 \\
Sharing $\xi=0.5$ & 71.2 & 69.9 & 73.9 & 85.4 \\
Sharing $\xi=0$ & 49.4 & 48.0 & 52.4 & 74.6 \\
\hline
\end{tabular}

\section{Estimation of the procurement cost decrease of cross-border procurement}

While the previous section presented a small numerical illustration to show the effect of reserve needs correlation and of asymmetry of procurement costs, this section estimates the possible cost decrease of cross-border procurement of automatic frequency restoration reserves $(\mathrm{aFRR})^{16}$ between Belgium, France, Germany, the Netherlands, Portugal and Spain. As discussed in section 2.2, Belgium, France, Germany and the Netherlands have already implemented imbalance netting and

\footnotetext{
${ }^{15}$ The relationship between the size of a TSO zone and its reserve need standard deviation $\sigma$ is not linear because larger countries already internalize their imbalance variability. If the correlation of reserve needs between regions of a TSO zone 1 is $\xi_{1}$ and this zone is $2^{n}$ times larger than an adjacent TSO zone 2 , then $\sigma_{1}=(\sqrt{2(1+\xi)})^{n} \sigma_{2}$. If $\xi_{1}=0.65, \sigma_{1}=6 \sigma_{2}$.

${ }^{16} \mathrm{aFRR}$ is used to bring the frequency back to its setpoint value in case of imbalances.
} 
jointly procure frequency containment reserves (FCR) in a weekly auction. However, they do not yet jointly procure aFRR. This section shows that the gains of exchanging and sharing aFRR are substantial. Our estimation differs from earlier studies (see 1), because it is not based on simulation but based on actual market data. To our knowledge, the only exception is (Vandezande et al., 2009) who estimate the cost decrease of a Belgium-Netherlands cross-border balancing market in 2008. Our study, however, estimates the cost decrease of cross-border exchange and sharing of aFRR for 2015-2016 in different subsets of Central West Europe (CWE) and Iberia. ${ }^{17}$

\subsection{Data}

We use price and quantity data of aFRR procurement in Belgium, France, Germany $^{18}$, the Netherlands, Portugal and Spain. The data are publicly available on the ENTSO-E Transparency Platform ${ }^{19}$ since the end of 2014. For each considered country $i$ and for each time instant $t$, these consist of a price $p_{i t}$ [ $€ / \mathrm{MWh}$ ] and procured capacity $R_{i t}[\mathrm{MW}$. The granularity of time instants goes from hourly (Portugal and Spain) to yearly (France). In Belgium, France and the Netherlands, only the average price of reserve procurement is reported, while Germany, Portugal and Spain report the marginal price of the procurement auction. The price and quantity data are complemented with imbalance data $r_{i t}$ [MWh], which has a granularity between 15 minutes and 1 hour. Table 4 summarizes the imbalance and procurement data in the considered European countries. The complete dataset consists of 105,264 values of $r, p$ and $R$. That is, 731 days of 24 hours for 6 countries.

We only present detailed results for procurement of positive reserves. However, as prices, procured capacities and imbalances are similar for negative reserves, their

\footnotetext{
${ }^{17}$ German TSOs already exchange aFRR capacity since December 1th 2007.

${ }^{18}$ German data also contain Luxembourg.

${ }^{19}$ To supplement and check the data, we have also used websites of the TSOs in the six countries. For example, German data of marginal prices comes from www.regelleistung.net, the platform for cooperation between the four German TSOs.
} 
Table 4: Summary of available imbalance and procurement data in considered European countries (Source: ENTSO-E Transparency Platform).

\begin{tabular}{lcccc}
\hline & $r_{t}$ & $R_{t}$ & Since & Price \\
\hline Belgium & 15 & weekly & 01.08 .2016 & average \\
& & monthly & 01.01 .2015 & average \\
France & 30 & yearly & 01.01 .2015 & average \\
Germany & 15, & weekly & 27.06 .2011 & marginal \\
Netherlands & 15 & monthly & 01.01 .2016 & average \\
& & yearly & 01.01 .2015 & average \\
Portugal & 60 & hourly & 13.12 .2014 & marginal \\
Spain & 60 & hourly & 12.12 .2014 & marginal \\
\hline
\end{tabular}

procurement cost decrease is comparable.

Table 5 presents summary statistics of the procurement and imbalance data. For both 2015 and 2016, this table reports the minimum, maximum and average procurement price and procured quantity. For example, the first row shows that in Belgium the marginal price of procurement ${ }^{20}$ is between $17.3 € / \mathrm{MWh}$ and 34 $€ / M W h$, with an average of $23.4 € / M W h$. The procured aFRR capacity is between 140 MW and 148 MW, with an average of 141 MW. Germany procures by far the largest amount of aFRR capacity, while Belgium, the Netherlands and Portugal procure the smallest amount of aFFR capacity. Average prices are lowest in Germany and highest in the Netherlands (2015) and Belgium (2016). The last column reports the positive imbalance value $r^{+}$[MW] that is not exceeded in $99 \%$ of hours with positive imbalance. $^{21}$ In European countries, the total reserve capacity of aFRR, mFRR and RR should be sufficient to cover this 99\% limit (European Commission, 2017b, art. 157.(2)(h)). Comparison of the two last columns shows that Germany satisfies this requirement with aFRR only, while the other five countries do not. Section 4.2 explains how we deal with this in our estimation.

In addition to the summary statistics of Table 5, Figure 6 shows the marginal

\footnotetext{
${ }^{20}$ See section 4.2 that deals with the calculation methodology.

${ }^{21}$ For reference, the hourly 2016 peak demand and average demand $[\mathrm{GW}]$ in the six countries are: France (81.2/53.4), Germany (57/48), Spain (40.1/28.5), Netherlands (19.7/13), Belgium (13.6/9.9) and Portugal (8.1/5.6) (Source: ENTSO-E Transparency Platform).
} 
Table 5: Summary of aFRR procurement data in considered European countries (Source: ENTSO-E Transparency Platform).

\begin{tabular}{lcccccccc}
\hline$[€ / \mathrm{MW} / \mathrm{h}]$ and $[\mathrm{MW}]$ & Year & $p_{\min }$ & $p_{\max }$ & $p_{a v}$ & $R_{\min }$ & $R_{\max }$ & $R_{a v}$ & $r_{99 \%}^{+}$ \\
\hline \multirow{2}{*}{ Belgium } & 2015 & 17.3 & 34 & 23.4 & 140 & 148 & 141 & 432 \\
\multirow{2}{*}{ France } & 2016 & 15.4 & 87.7 & 26.8 & 140 & 150 & 142 & 456 \\
\multirow{3}{*}{ Germany } & 2015 & 18.3 & 18.3 & 18.3 & 500 & 1177 & 647 & 2352 \\
\multirow{3}{*}{ Netherlands } & 2016 & 18.4 & 18.4 & 18.4 & 500 & 1100 & 639 & 2718 \\
\multirow{3}{*}{ Portugal } & 2015 & 2.58 & 24 & 7.2 & 2026 & 2500 & 2070 & 1739 \\
& 2016 & 1.88 & 24 & 5.6 & 1973 & 2500 & 2014 & 1541 \\
\multirow{3}{*}{ Spain } & 2015 & 27.4 & 27.4 & 27.4 & 300 & 300 & 300 & 992 \\
& 2016 & 14.1 & 21.3 & 17.8 & 170 & 170 & 170 & 896 \\
& 2015 & 5 & 61.4 & 20.5 & 66 & 322 & 171 & 697 \\
& 2016 & 4 & 80.1 & 16.6 & 56 & 333 & 173 & 860 \\
& 2015 & 2.1 & 121 & 19.6 & 467 & 913 & 685 & 3846 \\
& 2016 & 0.76 & 200 & 15.6 & 399 & 927 & 682 & 2447 \\
\hline
\end{tabular}

prices of aFRR in Belgium, France, Germany, the Netherlands and Spain for all hours of 01.01.2015 to 31.12.2016. Portuguese prices are not shown because they are close to the prices in Spain. ${ }^{22}$ As the hourly data of Germany and Spain is volatile, we report their 24-hour moving average. The price of the yearly auction in France is almost the same throughout the assessed period, while the prices in the Netherlands are constant and above French prices in 2015 but decrease in 2016, after moving to monthly auctions. Belgium, which went from monthly to weekly auctions after August 2016, saw a price spike at the end of 2016. This figure also shows that, except for Germany, price lines cross constantly. As a result, no single country is the most expensive at all times. In Germany, prices are almost consistently lower than in the other five countries.

Table 6 presents the correlation coefficients between imbalances in the six considered countries. These values are statistically different from zero at the $0.0001 \%$ level, except for the correlation between Netherlands and France, Portugal and Spain. As none of these country-pairs has a high positive correlation, significant efficiency gains of reserves sharing are possible.

\footnotetext{
${ }^{22}$ Prices in Portugal and Spain have correlation coefficient of 0.7 for 2015-2016.
} 
Figure 6: Marginal price of aFRR in Belgium, France, Germany, the Netherlands and Spain (01.01.2015-31.12.2016)

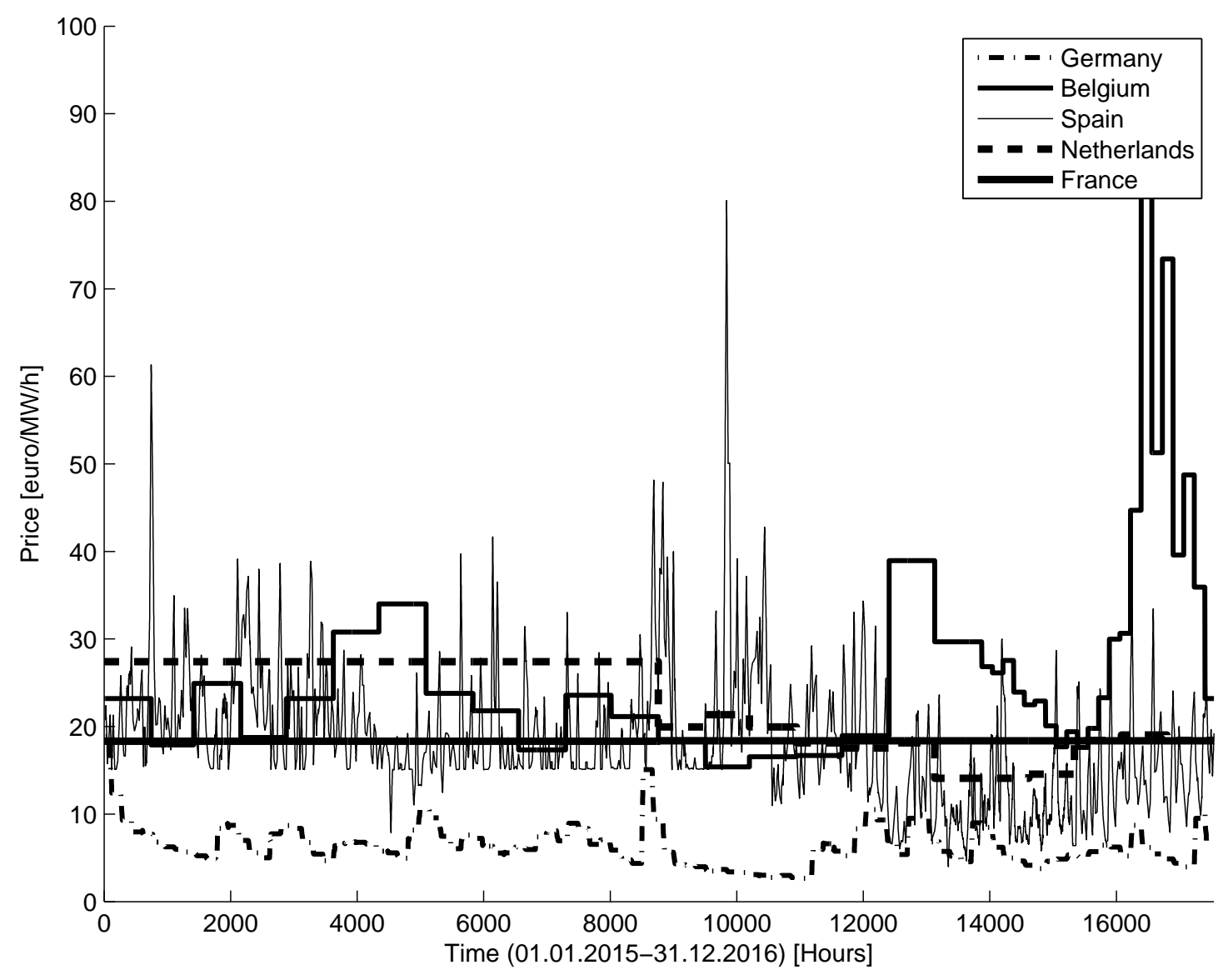

Table 6: Correlation coefficients between imbalances in the six considered countries (aFRR).

\begin{tabular}{lcccccc}
\hline & Belgium & France & Germany & Netherlands & Portugal & Spain \\
\hline Belgium & 1 & & & & & \\
France & 0.068 & 1 & & & & \\
Germany & -0.122 & -0.035 & 1 & & & \\
Netherlands & -0.160 & -0.005 & 0.094 & 1 & & \\
Portugal & -0.026 & -0.08 & 0.029 & 0.006 & 1 & \\
Spain & -0.038 & -0.051 & 0.060 & 0.005 & -0.019 & 1 \\
\hline
\end{tabular}




\subsection{Methodology}

First, we need to make an assumption on the functional form of the supply curves of generation reserves. Our only available information is the price-quantity pair for each of the 17544 hours for each country. Figure 7 plots these points for Germany, Spain, Belgium and Portugal. These plots clearly show that the supply curve is not constant throughout the period. Therefore, as there is only one pricequantity pair for each hour, we assume that for each considered country $i$ and for each hour $t$ the supply curve is linear between the origin and $\left(R_{i t}, p_{i t}\right)$ :

$$
b_{i t}=\frac{p_{i t}}{R_{i t}}
$$

Figure 7: Scatterplot of procurement price and quantity for Germany, Spain, Belgium and Portugal (01.01.2015-31.12.2016).
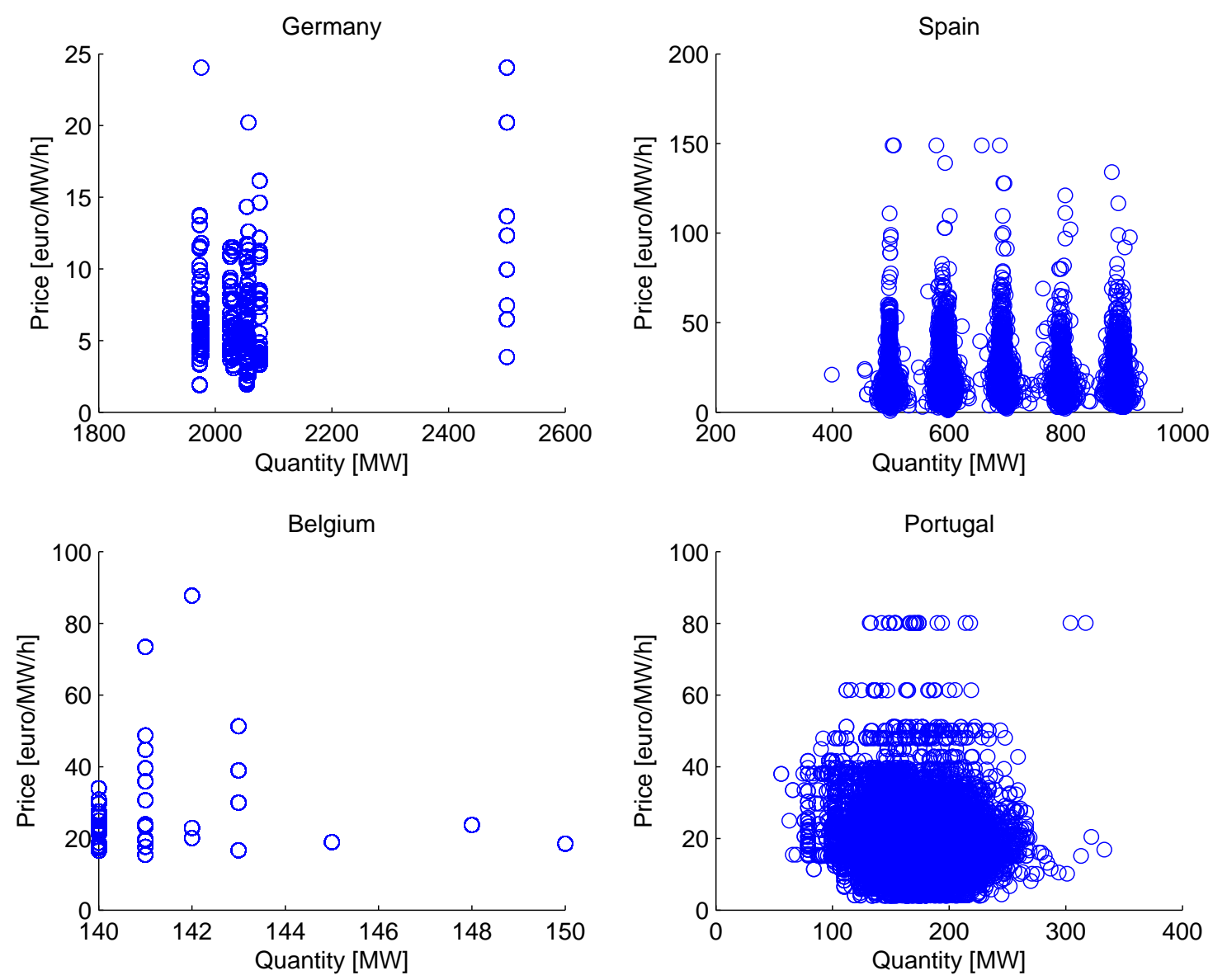

Second, in our dataset some countries report the average price while others the 
marginal price. As we assume supply to be linear, marginal prices are assumed to be twice the average price.

Third, as before, we do not focus on transmission capacity and assume that it never constraints cross-border cooperation. However, we illustrate the importance of an institutional constraint on reserves exchange and sharing. The European Commission (2017b) imposes that minimally $50 \%$ of required aFRR should be in the own country (exchange) and that required aFRR capacity can not decrease more than 30\%, compared to the autarkic level (sharing) (Baldursson et al., 2016). Results are shown both with and without these constraints.

\subsubsection{Reserves exchange}

The procurement cost decrease of reserve capacity exchange can be calculated using equation (6) in the case of two countries. Figure 8 shows their supply curves and the cost decrease is represented by the gray area. Generalizing this to exchange of generation reserve capacity between $n$ countries, the common marginal price of procurement $p_{\text {new }}$ for each hour $t$ is:

$$
p_{\text {new }}=\frac{\prod_{i=1}^{n} b_{i}}{\sum_{i=1}^{n} \prod_{j \neq i}^{n} b_{j}} \sum_{i=1}^{n} R_{i} \quad \text { with } \quad b_{i}=\frac{p_{i}}{R_{i}}
$$

Figure 8: The procurement cost decrease of reserves exchange between two countries

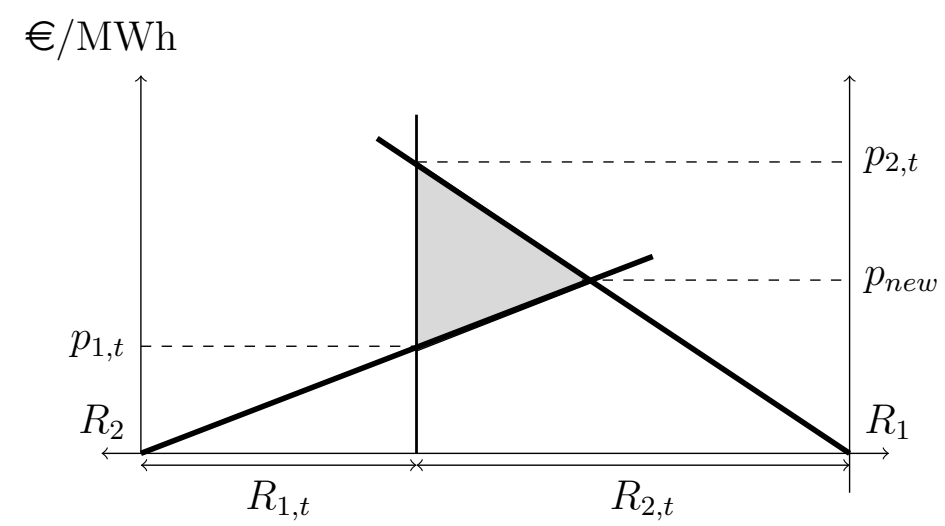

As the supply slopes are assumed to be linear, the decrease of procurement 
costs $\triangle P C$ due to cross-border exchange of generation reserve capacity for each hour $t$ is:

$$
\Delta P C=0.5\left(\sum_{i=1}^{n} R_{i} p_{i}-p_{\text {new }} \sum_{i=1}^{n} R_{i}\right)
$$

where $p_{i}$ and $q_{i}$ are the actual price and procured quantity in country $i$, and $p_{\text {new }}$ is the price determined by the common merit order and the total procured quantity of the $n$ countries that are exchanging reserves.

\subsubsection{Reserves sharing}

The gains from sharing of generation reserve capacity between $n$ countries are calculated using the following expression:

$$
v \operatorname{Pr}\left\{\sum_{i=1}^{n} r_{i}>\sum_{i=1}^{n} R_{i}^{s}\right\}=p_{\text {new }}
$$

where $p_{\text {new }}$ is calculated from (16) and the value of lost load (VoLL) $v$ is assumed to be $10,000 € /$ MWh. . This expression is the n-country generalization of equation (10). It shows that the total reserve capacity of $n$ reserve-sharing countries is optimal when the marginal expected interruption cost (left-hand side) equals the marginal cost of reserves (right-hand side). The country in which these reserves are procured depends on the countries' individual supply curves.

The cumulative distribution function of aggregate imbalances in $n$ countries is estimated based on the imbalance data $r_{i t}$ of 2015-2016. We see in the data that the probability distribution function of imbalances is a symmetrical bell-shaped curve with mean slightly above zero and fatter tails than the normal distribution. ${ }^{23}$

Again, we estimate the equation for each hour separately, which means that the total procured reserve capacity differs every hour, depending on $p_{\text {new }}{ }^{24}$ The

\footnotetext{
${ }^{23}$ In reality, obviously, it is estimated based on historical data, but since only little imbalance data prior to 2015 is available on the ENTSO-E Transparency Platform, we use 2015-2016 data. This should not greatly influence our estimation results.

${ }^{24}$ To simplify the procurement auction in reality, TSOs might choose $\sum_{i=1}^{n} R_{i}^{s}$ for a longer period, which decreases the possible gain.
} 
higher this price, the lower the procured reserve capacity.

The decrease of procurement costs $E$ from cross-border sharing of generation reserve capacity is also calculated from equation (17). However, as we can not make statements about the optimality of actual aFRR capacity that is currently procured in each of the six countries ${ }^{25}$, we will calculate the cost decrease relative to optimal autarkic reserves procurement, i.e. according to equation (4).

As noted before, European Commission (2017b, art. 157.(2)(h)) requires that the sum of procured aFRR, mFRR and RR should be sufficient to cover $99 \%$ of all imbalances. As we only study aFRR, but still need to link procured capacity to system imbalances to calculate the gains of aFRR sharing, the imbalance data are scaled by the ratio of average procured reserve capacity $\left(R_{a v}\right)$ and the required reserve capacity to cover $99 \%$ of all imbalances $\left(r_{99 \%}^{+}\right)$. This means that for all countries, except for Germany, the imbalance data are scaled down.

\subsection{Results}

To make comparison easy, the calculations are done separately for 2015 and 2016.

\subsubsection{Cost decrease due to reserves exchange}

Table 7 presents the decrease of procurement costs [million $€$ per year] due to reserves exchange between different sets of countries. The second and third column present results for 2015, while the last two columns present results for 2016. This estimation is only for procurement of positive aFRR, not for activation. Also note that we only focus on the cost decrease of procurement. The change of interruption costs (see section 3.6) is not assessed. For 2015, we estimate a procurement cost

\footnotetext{
${ }^{25}$ As the optimal trade off minimizes the sum of procurement and interruption costs, procurement costs can both increase or decrease when moving from the currently procured aFRR capacity to the optimal quantity with sharing.
} 
decrease of two-country reserves exchange of less than $€ 1$ million (Belgium-France and Belgium-Netherlands) up to $€ 19$ million (France-Germany). Gains are higher for 2016, except for Germany-Netherlands, as Dutch prices decreased in 2016. Evidently, the gains increase when more countries are cooperating. As their costs are similar, the gains due to exchange between Belgium, France and Netherlands are limited. However, when these countries exchange reserves with Germany, where costs are low, significant gains are possible. The total yearly gains of reserves exchange between the six countries exceed $€ 60$ million per year. The expected gains of exchanging positive and negative aFRR are thus around $€ 160$ million per year. Lastly, the third and fifth column show that the estimated gains decrease with only a few million $€$ per year by imposing the restriction that minimally $50 \%$ of the reserve requirement should be met locally.

Table 7: Cost decrease [M€/year] due to exchange of aFRR for different sets of countries.

\begin{tabular}{lcccc}
\hline [M€/year $]$ & \multicolumn{2}{c}{2015} & \multicolumn{2}{c}{2016} \\
& Unconstrained & Constrained & Unconstrained & Constrained \\
\hline Belgium-France & 0.88 & 0.88 & 2.89 & 2.77 \\
Belgium-Netherlands & 0.70 & 0.70 & 2.73 & 2.69 \\
Belgium-Germany & 7.13 & 6.36 & 10.59 & 9.02 \\
France-Germany & 18.94 & 17.88 & 24.37 & 22.32 \\
France-Spain & 6.68 & 6.67 & 9.74 & 9.58 \\
Germany-Netherlands & 19.44 & 17.28 & 6.46 & 5.78 \\
Portugal-Spain & 1.62 & 1.60 & 1.88 & 1.85 \\
\hline France-Portugal-Spain & 7.63 & 7.60 & 11.19 & 11.03 \\
Belgium-France-Netherlands & 3.57 & 3.57 & 3.24 & 3.11 \\
Belgium-Germany-Netherlands & 26.05 & 23.39 & 16.80 & 14.68 \\
\hline Belgium-France-Germany-Netherlands & 42.40 & 39.65 & 39.42 & 36.04 \\
\hline Belgium-France-Germany-... & \multirow{2}{*}{67.79} & 64.34 & 63.06 & 58.01 \\
\hline Netherlands-Portugal-Spain & & & & \multirow{2}{*}{} \\
\hline
\end{tabular}

This is a computation for the procurement of positive aFRR. Exchange of negative aFRR capacity leads to an additional $€ 100$ million per year. This is larger than the gain for positive aFRR because the price of German negative reserves is somewhat lower than of positive reserves. Only focusing on Central West Europe (CWE), exchange of negative reserves leads to around $€ 75$ million per year. The total gain of aFRR exchange is therefore around $€ 117$ million per year in the CWE 
area and around $€ 160$ million per year if all six countries cooperate.

\subsubsection{Cost decrease due to reserves sharing}

Table 8 presents the decrease of procurement costs [million $€$ per year] of reserves sharing between different sets of countries. As proven in section 3 , these are larger than the gains of exchange if the imbalance correlation is smaller than one. Table 8 shows that the gains of sharing are a multiple of the gains of exchange. The reason is that the imbalance correlations are close to zero. For example, the procurement cost decrease for Belgium-France, Belgium-Netherlands and PortugalSpain are low for exchange but considerably for sharing, because their marginal costs are similar but their imbalances have a low correlation. The yearly gains of two-country reserves sharing are $€ 22$ million (Belgium-Germany) up to $€ 75$ million (France-Germany), while the total yearly gains of reserves exchange between the six countries exceeds $€ 200$ million per year. The third and fifth column show that the constraints on reserves sharing have little effect on the estimated gains. Lastly, as noted before, the gains are estimated relative to procurement costs in case of optimal reserves procurement in autarky, i.e. according to equation (4). As the procured reserve capacity is not necessarily optimal in our data, the change of procurement costs from sharing will be different when compared to current procurement costs.

Sharing of negative reserves is estimated to lead to an additional $€ 350$ million in 2015 and $€ 300$ million in 2016, such that the total gain of aFRR sharing is between $€ 500$ and $€ 600$ million per year. Only focusing on the CWE area, sharing of negative reserves leads to an additional $€ 225$ million in 2015 and $€ 198$ million in 2016, such that the total gain of aFRR sharing is between $€ 370$ and $€ 310$ million per year.

The estimated gains of sharing depend on VoLL. A higher VoLL leads to a higher optimal reliability level and thus higher procurement costs. As a result, possible gains of sharing also increase. Table 9 shows that the procurement cost 
Table 8: Cost decrease [M€/year] due to sharing of aFRR for different sets of countries.

\begin{tabular}{lcccc}
\hline [M€/year $]$ & \multicolumn{2}{c}{2015} & \multicolumn{2}{c}{2016} \\
& Unconstrained & Constrained & Unconstrained & Constrained \\
\hline Belgium-France & 23.85 & 23.82 & 25.55 & 25.50 \\
Belgium-Netherlands & 28.51 & 28.51 & 24.18 & 24.18 \\
Belgium-Germany & 21.90 & 21.90 & 21.95 & 21.95 \\
France-Germany & 74.72 & 74.72 & 71.16 & 71.16 \\
France-Spain & 67.02 & 66.96 & 72.82 & 72.19 \\
Germany-Netherlands & 47.47 & 47.47 & 21.55 & 21.55 \\
Portugal-Spain & 49.36 & 48.36 & 42.41 & 41.68 \\
\hline France-Portugal-Spain & 108.56 & 103.15 & 101.44 & 95.88 \\
Belgium-France-Netherlands & 73.29 & 72.97 & 54.99 & 54.68 \\
Belgium-Germany-Netherlands & 69.37 & 69.37 & 43.25 & 43.25 \\
\hline Belgium-France-Germany-Netherlands & 142.83 & 142.83 & 114.48 & 114.48 \\
\hline Belgium-France-Germany-... & 249.27 & 248.68 & 205.74 & 205.35 \\
Netherlands-Portugal-Spain & & & & \multirow{2}{*}{} \\
\hline
\end{tabular}

decrease changes with around $€ 50$ million per year if VoLL is two times smaller or bigger.

Table 9: Sensitivity of procurement cost decrease $[\mathrm{M} € /$ year] to value of lost load $v$.

\begin{tabular}{cccc}
\hline year & $v=5,000$ & $v=10,000$ & $v=20,000$ \\
\hline 2015 & 200.60 & 249.27 & 307.6 \\
2016 & 165.85 & 205.74 & 251.27 \\
\hline
\end{tabular}

\subsubsection{Discussion}

As shown earlier in the numerical illustration of section 3.6, most of the procurement cost decrease is due to sharing, if marginal costs are similar and imbalances are not much correlated. However, when marginal costs differ substantially, as between Germany and its neighbors, exchange already leads to sizeable gains.

A limitation of our estimation is that we assume an unlimited linear supply curve between the price-quantity pair and the origin. However, the Spanish TSO makes the hourly supply curves of aFRR publicly available ${ }^{26}$. These show that a linear curve through the origin is a good approximation of the actual supply curve

${ }^{26}$ https://www.esios.ree.es 
up to a certain level. As an indication, the supply curve at 3am and $7 \mathrm{pm}$ every 10th day of all 24 months of 2015-2016 is approximately linear through the origin up to $183 \%$ of procured capacity. As a robustness check we have imposed this limit in our numerical analysis, but the results do not change much.

Another limitation of our estimation is that we assume that cross-border flows due to reserves cooperation are never constrained. However, this is in line with European regulation, which requires TSOs to specifically allocate cross-zonal transmission capacity to exchange or sharing of reserve capacity up to the point where it is economically efficient (European Commission, 2017a, Title IV). This means that, if procurement of reserve capacity and dispatch of energy are done simultaneously, the price difference between countries should be equal in both markets, in case of transmission congestion:

$$
\Delta \gamma=\gamma_{1}-\gamma_{2}=\Delta p_{\text {dispatch }}
$$

This somewhat decreases our estimated gains, but does not affect reliability, as cross-zonal transmission capacity is specifically allocated for cross-border reserves cooperation. As a result, the coordination issues identified by Van den Bergh et al. (2017) will not occur.

Van den Bergh et al. (2017) estimate the gains of reserves exchange and sharing in the CWE area to be respectively $€ 40$ and $€ 50$ million per year, while this paper estimates these to be respectively $€ 117$ and above $€ 310$ million per year for aFRR. The difference in magnitude could be due to their use of data on installed generation capacity to estimate the reserve and energy supply curve, while our study uses actual data on market prices and quantities. In addition, they only focuses on imbalances stemming from wind and solar forecast errors, while our study uses actual data on system imbalances. This could explain why our study finds much larger gains for sharing than their study.

A possible avenue for future research is to combine engineering simulation stud- 
ies with economic analysis and market data. Price and quantity data can improve the estimation of reserve and energy supply curves based on installed generation capacity.

\section{Implementation of cross-border reserves pro- curement}

Whenever TSOs start exchanging and sharing reserves, there are gains and distributional effects. This section first analyses how the benefits of cooperation are distributed. Next, we study what institutions improve the incentive for cooperation.

We consider first the autarkic TSO case. In this case, each TSO can implement a market mechanism to minimize the procurement costs of the reserves required. Next we discuss the distributional effects of reserves exchange via a uniform-price auction. These effects can be negative for one of the parties so that compensation mechanisms need to be put in place to guarantee cooperation. We develop a Nash bargaining game to study the compensation necessary for TSOs to agree on exchange of reserves. This game can be defined for regulated reliability levels as well as for optimized reliability levels.

\subsection{Optimal autarkic TSO reserve provision}

The analysis of the previous section is based on the premise that the TSO (in lieu of a social planner) has direct control of the available reserves. In a marketbased system this is not the case and the reserves have to be procured by some market mechanism. Here we assume a uniform-price auction with the resulting price $p_{i}{ }^{27}$ The TSO now determines the level of reserves $R_{i}$ that minimizes the

\footnotetext{
${ }^{27}$ Some TSO zones use pay-as-bid clearing but this is considered to be less preferable (Neuhoff and Richstein, 2016).
} 
cost of procurement and the cost of interruptions:

$$
\min _{R_{i}}\left\{v \int_{R_{i}}^{\infty}\left[r_{i}-R_{i}\right] f_{i}\left(r_{i}\right) d r_{i}+p_{i}^{a} R_{i}\right\}
$$

This results in the first-order condition for the optimal level of reserves.

$$
v \operatorname{Pr}\left\{r_{i}>R_{i}\right\}=p_{i}^{a} .
$$

Generation firms supply the reserves. We assume they do not exercise market power and take prices as given, so generators will bid up to the point where marginal procurement costs equal the reserves price, i.e. where

$$
\gamma_{i}^{\prime}\left(R_{i}\right)=p_{i}^{a}
$$

The market equilibrium is determined by (21) and (22). Clearly, equation (4) follows from these two conditions so the market equilibrium coincides with the first-best level of reserves in autarky. In a market implementation the resulting reserves price is $p_{i}^{a}$.

\subsection{Reserves exchange}

\subsubsection{Regulated reserves levels without inter-TSO compensation}

Now suppose we are in a more realistic setting where, instead of a joint minimization of costs, each TSO minimizes its own costs, subject to the constraint that regulatory reserve levels must be met. As in the autarkic setting, we assume reserves in each TSO zone are procured by a uniform-price auction and, moreover, that these auctions are run simultaneously. Since exchange is unfettered, prices and marginal procurement costs will be equal in the two zones, i.e.

$$
p^{e}=\gamma_{1}^{\prime}\left(R_{1}\right)=\gamma_{2}^{\prime}\left(R_{2}\right)
$$

where $p^{e}$ denotes the price of reserves in exchange, common to the two zones. Comparing (23) to (6), since each TSO will procure the level of reserves required 
by regulation, it is clear that the market solution achieves the cost-minimizing outcome.

\subsubsection{Inter-TSO transfers to guarantee cooperation}

In a transition from autarky to exchange, the reserves price will rise in the cheap zone where marginal procurement costs are lower in autarky than in exchange, and fall in the expensive zone where these costs are higher. Hence, the TSO in the cheap zone will not have an incentive to participate in joint procurement auctions without compensation. Figure 9 shows this situation, with Zone 1 being the cheaper and Zone 2 the more expensive. The financial gain of TSO 2 corresponds to area $\mathrm{C}+\mathrm{D}$, whereas the loss of TSO 1 corresponds to area A. TSO 1 can compensate TSO 2 for his loss and retain some surplus provided $C+D>A$.

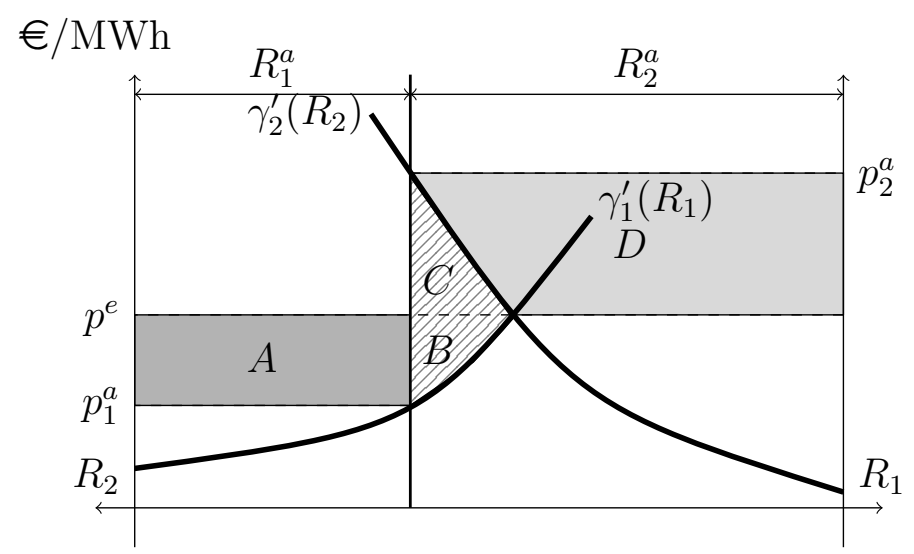

Figure 9: Cost minimization under reserves exchange between two TSO zones. Area A indicates the procurement cost increase of TSO 1; area $\mathrm{C}+\mathrm{D}$ indicates the procurement cost decrease of TSO 2.

If the cross-border reserves procurement is organized via a uniform-price auction, we need transfers between the TSOs to guarantee cooperation. We will analyse the situation where there are lump-sum transfers. ${ }^{28}$ In principle, there are infinitely many solutions to the bargaining game between the two TSOs, as long as a bargaining solution is feasible. Here we use the approach of the Nash bargaining game (Nash,

\footnotetext{
${ }^{28}$ Another possibility is a distortionary tax on import or export. However, such a tax would reduce the gains from trade.
} 
1953; Binmore et al., 1986) and assume that the autarkic solution is the fallback for both TSOs. Assuming consumers are compensated for interruptions, total costs for TSO $i$ in autarky are $C_{i}^{a}=p_{i}^{a} R_{i}^{a}+L_{i}$, where $L_{i}=v \int_{R_{i}}^{\infty}\left[r_{i}-R_{i}^{a}\right] f_{i}\left(r_{i}\right) d r_{i}$ are expected interruption costs. ${ }^{29}$ We denote the lump-sum side payment from TSO 2 to TSO 1 by $x$. Similar to (Kolstad, 2005), the side payment can be interpreted as a measure of difficulty to make an agreement.

With exchange the TSOs have the following costs:

$$
\begin{aligned}
& C_{1}^{e}=p^{e} R_{1}^{a}+L_{1}+x \\
& C_{2}^{e}=p^{e} R_{2}^{a}+L_{2}-x
\end{aligned}
$$

Assuming equal bargaining power of the two TSOs the Nash product is given by

$$
N=\left[\left(p_{1}^{a}-p^{e}\right) R_{1}^{a}+x\right]\left[\left(p_{2}^{a}-p^{e}\right) R_{2}^{a}-x\right]
$$

and the first-order condition for maximum with respect to $x$ turns out to be

$$
x^{*}=\frac{1}{2}\left[\left(\left(p_{2}^{a}-p^{e}\right) R_{2}^{a}-\left(p_{1}^{a}-p^{e}\right) R_{1}^{a}\right)\right] .
$$

That is, the transfer is $0.5(A+C+D)$. The drop in costs for TSO $i$, going from autarky to exchange with bargaining and side payment is seen to be

$$
C_{i}^{a}-C_{i}^{e}=\frac{1}{2}\left[\left(\left(p_{2}^{a}-p^{e}\right) R_{2}^{a}-\left(p^{e}-p_{1}^{a}\right) R_{1}^{a}\right)\right]
$$

The right-hand side of (26) is half the net financial surplus resulting from reserves exchange $(\mathrm{C}+\mathrm{D}-\mathrm{A})$. If one TSO has a stronger bargaining position than the other this result would not be reached. In this case the stronger TSO would gain more of the surplus. The basic result that a positive financial surplus is necessary for a bargaining solution to be feasible would, however, clearly still hold.

The analysis above assumes that a TSO only cares about its procurement

\footnotetext{
${ }^{29}$ Since required reserve levels are the same as in autarky it is in fact irrelevant whether consumers receive compensation. This is no longer the case when reserve levels are allowed to adjust to changed marginal reserve procurement costs.
} 
costs. In reality, however, a TSO is also concerned about social welfare in its zone, in part because increased costs of reserves procurement are charged to consumers through network tariffs, and therefore do not affect TSO profits. Including this welfare concern into the TSO utility function increases the willingness to cooperate. Suppose that a TSO has a preference $\alpha \in[0,1]$ for social welfare $(\mathrm{SW})$ and $(1-\alpha)$ for a decrease of procurement costs (PC). It favours cooperation if:

$$
\Delta U_{i}=\alpha \Delta S W_{i}-(1-\alpha) \Delta P C_{i} \geq 0
$$

With a lump sum transfer $y$ the TSOs have the following changes of utility:

$$
\begin{aligned}
& \Delta U_{1}=\alpha \Delta S W_{1}+(1-\alpha)\left(p_{1}^{a}-p^{e}\right) R_{1}^{a}+y \\
& \Delta U_{2}=\alpha \Delta S W_{2}+(1-\alpha)\left(p_{2}^{a}-p^{e}\right) R_{2}^{a}-y
\end{aligned}
$$

where $\Delta S W_{1}$ equals area $\mathrm{B}$ and $\Delta S W_{2}$ equals area $\mathrm{C}$ in Figure 9. Assuming equal bargaining power of the two TSOs the Nash product is given by

$$
N=\left[\alpha \Delta S W_{1}+(1-\alpha)\left(p_{1}^{a}-p^{e}\right) R_{1}^{a}+y\right]\left[\alpha \Delta S W_{2}+(1-\alpha)\left(p_{2}^{a}-p^{e}\right) R_{2}^{a}-y\right]
$$

and the first-order condition for maximum with respect to $y$ turns out to be

$$
y^{*}=(1-\alpha) x^{*}+\alpha \frac{\Delta S W_{2}-\Delta S W_{1}}{2}
$$

That is, if a TSO also cares about social welfare in its zone, the lump sum transfer is lower, which is an indication that voluntary cooperation is easier (Kolstad, 2005).

Proposition 2. If a TSO, in addition to procurement costs, also cares about social welfare in its zone, the lump sum transfer needed for cooperation is lower: If $\alpha>0$, $y^{*}<x^{*}$

Proof. If $\alpha>0, y^{*}<x^{*} \Leftrightarrow \frac{\Delta S W_{2}-\Delta S W_{1}}{2}<x^{*}$, where $\frac{\Delta S W_{2}-\Delta S W_{1}}{2}=0.5(C-B)$ and $x^{*}=0.5\left[\left(\left(p_{2}^{a}-p^{e}\right) R_{2}^{a}-\left(p_{1}^{a}-p^{e}\right) R_{1}^{a}\right)\right]=0.5(D+C+A)$. Therefore $y^{*}<x^{*} \Leftrightarrow$ $A+B+D>0$. Since areas $A, B$ and $D$ are positive, $y^{*}<x^{*}$. 
Thus, in regions without an obligation to cooperate, cost-reducing cross-border cooperation will only materialize if all TSOs reap the benefits of cooperation. This can be ensured with side payments, which can be both the explicit value of our analysis (as in the inter-TSO compensation mechanism) or more implicitly (e.g. distortionary import tariffs or transaction costs to join the cross-border cooperation platform); see further discussion in the Conclusions.

\subsubsection{Locally optimal reserves levels}

In the case of locally optimal reserve levels, not only costs of reserves, but also expected consumer interruption costs will change. Hence, the feasibility of a bargaining solution and side payments will be affected. Basic insights, however, remain the same as in the previous case.

\subsection{Reserves sharing}

As in the case of reserves exchange there are, in general, distributional consequences of reserves sharing that may make one zone better off and the other worse off, both as regards procurement costs and expected interruptions. ${ }^{30}$ Similar to reserves exchange, incentive compatibility of sharing requires a minimal side payment from the zone that gains the most to the one that is worse off and a bargaining outcome can be predicted using the Nash bargaining solution. If there is sufficiently low correlation in reserve needs between the two zones, it is, however, possible that the gains from lower interruption costs due to integration outweigh any rise in reserves procurement costs. An extreme example of this is when the two zones have perfectly negatively correlated reserve needs. In this case reserve sharing eliminates any needs for reserve procurement! This is, however, unlikely to be the case in real situations.

\footnotetext{
${ }^{30}$ With reserves sharing, assigning procurement costs to TSOs is ambiguous since the decrease depends on the correlation of reserve needs between the TSO zones. In addition, expected interruption costs in each TSO zone depend on how interruptions are shared. For example, if interruptions are shared in equal proportions, the distribution of expected interruption cost is different than if the reserves-providing TSO has priority over the reserves-receiving TSO.
} 


\section{Conclusions}

This paper compares three degrees of TSO cooperation in generation reserves provision: autarky, reserves exchange and reserves sharing. We derive analytically the optimal procurement of reserves in each of the three cases and show that costs decrease with cooperation. The benefits of reserves exchange and reserves sharing depend on cost asymmetry and correlation of real-time imbalance variability between cooperating TSO zones. That is, when TSO zones have highly asymmetric reserve procurement costs but highly correlated reserve needs, reserves exchange already yields a high cost reduction. When TSO zones have fairly equal reserve procurement costs but a low degree of reserve needs correlation, reserves sharing is needed to reap the full benefits of TSO reserves cooperation.

Based on actual 2015-2016 market data of reserves procurement of positive and negative automatic frequency restoration reserves in Belgium, France, Germany, the Netherlands, Portugal and Spain, we estimate the efficiency gains of exchange and sharing for different subsets of these countries. Cross-border cooperation in these six countries leads to around $€ 160$ million per year for exchange and around $€ 300$ million per year for sharing. In the CWE area, the gains are respectively around $€ 117$ and $€ 310$ million per year.

Our analysis shows that cross-border reserves cooperation has distributional impacts on TSOs; some TSOs may even experience an increase of procurement costs. This can be a factor hindering cooperation of TSOs on cross-border reserves procurement and balancing and thus prevent potential efficiency gains from being realised $^{31}$. In general, the extent of the disincentives created by such distributional impacts will depend on the market mechanisms in place in different areas as well as on the weight TSOs place on social welfare, rather than their own costs; cooperation

\footnotetext{
${ }^{31}$ This is perhaps illustrated by the elimination of an obligation to cooperate on balancing and reserves procurement, initially included in the proposed Electricity Balancing Guideline (?), but now dropped in the recently adopted guideline (?).
} 
will be easier when TSOs place a weight on social welfare in their zone. This underscores the importance of careful design of regulation and mechanisms for trade, as well as for redistribution of efficiency gains. We illustrate, in the context of a particular market mechanism (uniform price auctions), how side payments can be used to induce cooperation. Full analysis of these issues is beyond the scope of this paper, but is, however, an important area for further research.

In this paper we focused on the changes of procurement and interruption costs generated by more efficient supply. The true benefits of cross-border cooperation can be higher than presented in our model because of improved market liquidity, internalisation of external effects, and increased market access through standardization of rules and products. In addition, TSOs that are first to cooperate can define the rules and standards of cooperation and have therefore lower transaction and compliance costs.

\section{Acknowledgements}

We are grateful for very helpful comments from Claude Crampes, ThomasOlivier Léautier and seminar participants at the IAEE 2016 conference in Bergen. The research leading to these results is partly funded by the European Union Seventh Framework Programme (FP7/2007-2013) under grant agreement No 608540, project acronym GARPUR. While carrying out this research Fridrik Baldursson has been associated with CREE - Oslo Centre for Research on Environmentally friendly Energy. CREE is supported by the Research Council of Norway. All remaining errors are our own.

\section{References}

50Hertz Transmission GmbH, Amprion GmbH, Elia, GmbH, T. T., and 
TransnetBW GmbH (2014). Potential cross-border balancing cooperation between the Belgian, Dutch and German electricity Transmission System Operators. (October).

Baldursson, F. M., Lazarczyk, E., Ovaere, M., and Proost, S. (2016). Multi-TSO system reliability: cross-border balancing. Energycon proceedings.

Binmore, K., Rubinstein, A., and Wolinsky, A. (1986). The Nash bargaining solution in economic modelling. The RAND Journal of Economics, 17(2):176-188.

CAISO (2017). Quantifying EIM Benefits, 2017 Q1 Report. Technical report.

Doorman, G. L. and Van der Veen, R. (2013). An analysis of design options for markets for cross-border balancing of electricity. Utilities Policy, 27(January 2011):39-48.

Ela, E., Milligan, M., and Kirby, B. (2011). Operating Reserves and Variable Generation. Technical Report August.

ENTSO-E (Accessed: 1st of August 2016). Public consultation for the design of the terre. https://consultations.entsoe.eu/markets/terre.

European Commission (2017a). Commission Regulation (EU) 2017/000 [EB] establishing a guideline on electricity balancing.

European Commission (2017b). Commission Regulation (EU) 2017/000 [SO] establishing a guideline on electricity transmission system operation.

Farahmand, H., Aigner, T., Doorman, G. L., Korpas, M., and Huertas-Hernando, D. (2012). Balancing market integration in the northern european continent: A 2030 case study. IEEE Transactions on Sustainable Energy, 3(4):918-930.

Gebrekiros, Y. T., Doorman, G. L., Farahmand, H., and Jaehnert, S. (2013). Benefits of cross-border reserve procurement based on pre-allocation of transmission capacity. In PowerTech (POWERTECH), 2013 IEEE Grenoble, pages 1-6. IEEE. 
Hobbs, B. F., Rijkers, F. A., and Boots, M. G. (2005). The More Cooperation, the More Competition? A Cournot Analysis of the Benefits of Electric Market Coupling. The Energy Journal, 26(4):69-97.

Just, S. (2015). The german market for system reserve capacity and balancing. EWL Working Paper.

Kolstad, C. D. (2005). Piercing the veil of uncertainty in transboundary pollution agreements. Environmental and Resource Economics, 31(1):21-34.

Mott MacDonald (2013). Impact Assessment on European Electricity Balancing Market. (March):1-135.

Nash, J. F. (1953). Two-Person Cooperative Games. Econometrica, 21(1):128-140.

Neuhoff, K. and Richstein, J. (2016). Coordinated Balancing of the European Power System.

NREL (2011). Flexibility Reserve Reductions from an Energy Imbalance Market with High Levels of Wind Energy in the Western Interconnection. Technical Report October.

Ovaere, M. and Proost, S. (2016). Electricity transmission reliability: the impact of reliability criteria.

Tangerås, T. P. (2012). Optimal transmission regulation of an integrated energy market. Energy Economics, 34(5):1644-1655.

Transpower (2013). Ancillary services procurement plan. Technical Report December.

Van den Bergh, K., Hytowitz, R. B., Delarue, E., William, D., and Hobbs, B. (2017). Benefits of coordinating sizing, allocation and activation of reserves among market zones. Electric Power Systems Research, 143:140-148. 
van der Weijde, A. H. and Hobbs, B. F. (2011). Locational-based coupling of electricity markets: benefits from coordinating unit commitment and balancing markets. Journal of Regulatory Economics, 39(3):223-251.

Vandezande, L., Saguan, M., Meeus, L., Glachant, J. M., and Belmans, R. (2009). Assessment of the implementation of cross-border balancing trade between Belgium and the Netherlands. 2009 6th International Conference on the European Energy Market, EEM 2009, pages 1-6.

Zhou, Z., Levin, T., and Conzelmann, G. (2016). Survey of U.S. Ancillary Services Markets. Technical report, Center for Energy, Environmental, and Economic Systems Analysis, Energy Systems Division, Argonne National Laboratory. 